\title{
Artigo
}

Resumo

Objetivamos nesse trabalho refletir, apoiados na teoria psicanalitica, sobre a (im)possibilidade da transmissão da ética da Psicanálise a práticas que se situam fora dos moldes da clínica tradicional. Vimos que isso é possivel, desde que sustentemos a ideia de que essa transmissão se dá quando o agente de cuidado atua a partir da condição de sujeito castrado. A teoria lacaniana sobre a função do mais um foi importante para pensarmos na montagem de dispositivos que regulem as intervencões clínicas, na medida em que pode operar como função que atualiza a castração do Outro interventor, descompletando o saber médico-psicológico (universitário).

Descritores: ética; psicanálise; saúde mental; Jacques Lacan.

\section{REFLEXÕES SOBRE A ÉTICA DA PSICANÁLISE E SUA CONTRIBUIÇÃO PARA PRÁTICAS DE SAÚDE MENTAL}

\author{
Carolina Andrade de Santana Lima \\ João Luíz Leitão Paravidini
}

O principal objetivo deste trabalho é promover a reflexão, a partir das teorizações psicanalíticas de Freud e Lacan, sobre a (im)possibilidade da transmissão da ética psicanalítica a práticas que se situam fora dos moldes da clínica tradicional. Acreditamos que essa é uma prática possível, desde que apoiada na ideia de que, transmitir essa ética, significa atuar a partir da condição de sujeitos castrados, ou seja, criar condições para que a transmissão da

- Mestre pelo Instituto de Psicologia da

Universidade Federal de Uberlândia. Psicóloga do CAPS Oeste de Uberlândia. Professora do curso de Psicologia da Faculdade Pitágoras.

- Professor adjunto da Universidade Federal de Uberlândia. 


\section{Artigo}

Lei - que interdita a tomada do sujeito como objeto de um saber suposto todo - se mantenha operante.

A posição de onde se articula toda e qualquer intervenção deve ser, portanto, contrária a toda pretensão universalizante e totalizante, quer esta tome a forma de regras morais, ou de um saber médico-psicológico que torne a priori a emergência do sujeito um fato de difícil acontecimento. Nesse sentido, buscamos a teoria lacaniana sobre a função do mais um, entendendo que esta pode ser útil para pensarmos na montagem de um dispositivo que funcione como um regulador da ética das intervenções, na medida em que ele pode operar como o que atualiza a castração do Outro interventor, descompletando o saber médico-psicológico (universitário). O mais um, como veremos, pode funcionar como um agente que, aponta e denuncia os momentos em que as transferências podem fazer obstáculo à transmissão da Lei e da castração, a partir da qual, o sujeito pode advir. Sendo assim, nos parece possível articular essa teoria com as práticas de cuidado já existentes nos projetos existentes no âmbito da Saúde Pública, uma vez que a estruturação da equipe multidisciplinar em torno de uma desespecialização do saber médico (estrutura que caracteriza a organização do Programa de Saúde da Família, por exemplo), propicia uma montagem institucional mais próxima daquilo que estamos propondo como possibilidade de atuação ética, apesar de, como vere- 
mos, não ser possível sustentá-la durante todo o tempo, devido às barreiras narcísicas e institucionais que acompanham todo e qualquer funcionamento grupal.

Para tal reflexão, abordamos alguns aspectos teóricos que, nos auxiliam no percurso de analisar como práticas que não se enquadram nos moldes da clínica psicanalítica clássica podem estar perpassadas por uma ética do desejo, ou seja, aquela que coloca o sujeito diante da própria falta, e, consequentemente, do conflito que constitui nossa condição de castrados (Kehl, 2002). Para isso, fazemos menção a um caso atendido por nós durante nossa experiência como analistas locados em uma unidade de saúde da família de nosso município.

Trata-se de uma família formada por quatro mulheres. Ou melhor, cinco, pois ao final do tempo de acompanhamento dessa família, a quinta integrante, a filha que preferia ficar na rua por considerá-la a sua casa, retornou para junto de sua mãe e irmãs, trazendo no ventre um bebê.

Gravidez não era o problema ali. Ou será que era? A menina mais nova, de treze anos, estava tendo a sua primeira experiência, a segunda filha (que não era a mais velha) já tinha tido dois filhos, ambos tomados pelo Conselho Tutelar, e a mais velha, a que morava na rua, também. A mãe tinha tido outros filhos, se nos lembramos ao certo, o total eram 11. Cada um em um lugar, diferentes cidades, diferen- tes estados. Confundia-se ao mencionar, e, por isso, nos parece, às vezes, tão difícil contar. Uns morreram, um ou outro ela deixou com parentes e outro ou um o Conselho tirou. Restaram as quatro meninas, que seguiam a mãe por onde quer que ela fosse. Além das gravidezes dessas mulheres; meninas; mulheres-meninas, tínhamos também que lidar com o problema das drogas, pois todas elas faziam uso de crack.

Moravam na casa de um homem que, em troca de alguns favores, deixou-as ficar. Não havia energia, rede de esgoto, e a sujeira tomava conta dos cômodos improvisados como quartos. Ao percebermos a gravidez da menina mais nova, perguntamos se não queria ir conosco até a unidade. A essa altura, víamos que não era possível marcar um horário, nem solicitar jejum. Começávamos a entender que elas estavam fora. Fora da lógica, que, não raro, nos parece ser a única, de funcionamento social.

Acompanhamo-las por algum tempo. Tempo suficiente para que o bebê da menina mais nova nascesse. Chegamos muito perto dessa família, uma vez que entendemos que elas não frequentariam a unidade de saúde. Resolvemos então ir até elas, conhecer o seu canto, o seu mundo, as suas regras. E, ao perceber que não encontraríamos soluções para resolver tantos problemas com os quais nos deparávamos a cada visita, entendemos que estávamos lidando com clínica que exigia uma leitura singular. 


\section{Artigo}

\section{A condição paradoxal como forma de subjetividade contemporânea}

O fragmento do caso apresentado nos suscita muitos questionamentos sobre as (im)possibilidades de atuação como profissionais de saúde. Ele exemplifica uma maneira de funcionamento singular, mas, ao mesmo tempo, ilustrativo de uma série de outras famílias que temos encontrado em nossa prática e que colocam o nosso saber à prova.

Ao refletirmos sobre o caso que relatamos, pensamos nessa família como representante de algumas ideias que vêm surgindo com autores que procuraram fazer avançar a teoria psicanalítica, tendo sempre como base seus norteadores fundamentais, em especial, a ética. Parece-nos interessante pensar nesse caso mediante a apresentação que Rassial (2000) nos faz do sujeito em estado limite, para podermos entender esse clã como sujeitos que parecem estar fora de uma estruturação clássica proposta pela psicanálise, permitindo-nos uma leitura singular a partir das formas de funcionamento do sujeito contemporâneo. Isso porque o autor faz uma relação íntima entre o estado limite e o declínio da função paterna. Diferentes autores dão diferentes nomes para essa perspectiva diagnóstica. Miguelez (2007) parece preferir falar em subjetividades contemporâneas, 


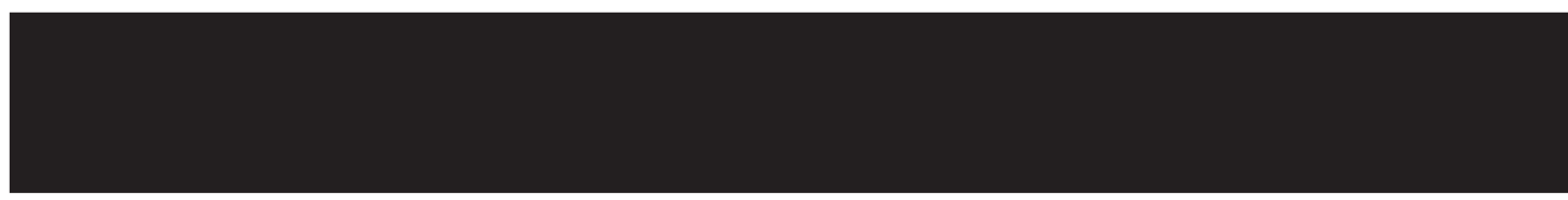

nas quais ela, juntamente com outros autores aos quais ela faz menção, situa sujeitos que estão em uma relação paradoxal com o simbólico, em que o atravessamento pelas interdições fundantes da cultura, que, antes, fora garantido pela função paterna e, agora, por novos dispositivos de poder parecem, na maioria das vezes, não se sustentarem.

O fato é que essas mulheres nos convidam a pensar sobre uma forma outra de funcionamento social/psíquico. Ao ouvir o relato do caso a impressão que nos dá é de sujeitos que parecem não estar submetidos ao mesmo laço social que o nosso: não cumprem horários, não sabem em que dia da semana estão, não sabem seu nome nem sobrenome, não vão ao médico, não tem documentos. No entanto, ao estar com essas mulheresmeninas, quem parece estar fora somos nós. Esta se presume o que chamaremos de condição paradoxal encontrada nessas estruturas familiares: a condição de sujeitos que parecem estar fora e dentro da lei, em uma relação peculiar com o laço social.

Numa das poucas oportunidades que tivemos de levar as meninas para a unidade de saúde, entramos com elas na sala para tentarmos conversar um pouco. Ficaram mudas. Uma delas, a do meio, declarou que não sabia dizer de si, não sabia contar sua história, pois sua vida era a droga. E essa julgamos ser a sua única condição de existência.

Assim, seu modo de laço social não parece se inserir no que podería- mos chamar de lógica neurótica padrão, pois, citando as palavras da Kehl (2002), tudo o que um neurótico quer é um lugar de ser, e esta dimensão parece não ter sido constituída para este clã. Não estamos, aqui, pretendendo fazer uma leitura estrutural dessa família. Além de não ser nosso objetivo, acreditamos que isso demandaria uma análise mais aprofundada do caso o qual é ser rico justamente por, como já assinalamos, estar fora. Isso inclui, a nosso ver, estar fora da possibilidade de enquadrar essas mulheres-meninas numa única estrutura psicanaliticamente falando. Uma outra questão que consideramos importante levantar para este trabalho, é que o que temos como consequência de uma neurose de transferência em casos clássicos de sujeitos neuróticos, seria a demanda de amor e reconhecimento a qual o próprio paciente passa a fazer para seu analista. "Demandas de amor dirigidas ao Outro enquanto autoridade, enquanto sujeito suposto saber" (Kehl, 2002). Temos nos deparado, em nossa prática, com famílias nas quais não há demanda de amor, aliás, não há demanda, e isso tem nos chamado muito a atenção. O que fazer se não há demanda? $\mathrm{E}$, ainda, o que fazer com a angústia dos agentes de saúde - e aqui incluímos todos aqueles que têm por objetivo cuidar, independente de sua formação técnica - ante a ausência dessa demanda. Temos nos atentado para essa singular forma de estar no mundo, que exige dos profissionais de saú- 
de maneiras também singulares de cuidado. Tomamos, mais uma vez, a obra de Rassial (2000), na qual ele afirma a existência de modos de ser que não estão, necessariamente, incluídos em uma estrutura específica, algo que escapa às definições clássicas da psicopatologia: são "testemunhos, frequentemente dolorosos, de um estado do pensamento, do desejo e dos laços familiares e sociais" (Rassial, 2002, p. 171).

São justamente esses casos, essas estruturas de funcionamento familiar, que muito nos impõe a certeza quanto à impossibilidade de se gerar produções e intervenções que não pautem pela irredutibilidade da condição alteritária, assim como pelas diferenças marcantes de crenças, valores e modos de se viver existentes entre estas famílias e os profissionais que delas cuidam.

\section{A ética da Psicanálise}

Ao propormos uma clínica que se sustente na ideia de que não é possível uma tecnização do cuidado, a Psicanálise surge como uma teoria que pode nos auxiliar a pensar o cuidado na medida em que se ancora numa ética que se que se dedica a entender "o homem diante do drama da liberdade e alienação ao inconsciente, esse estranho que age nele e do qual ele não pode se descomprometer" (Kehl, 2002, p. 33). Kehl (2002) assevera ainda que, por ser o primeiro pensamento que coloca em crise os pressupostos da ética kantiana no séc. XX, ao cindir o homem por meio da teoria do inconsciente, a Psicanálise "não pode propor nenhuma verdade definitiva sobre natureza humana e seu bem supremo, porque parte do princípio de que o homem, sobretudo na modernidade, é vazio de ser" (p. 34). Assim, acreditamos que só é possível articular Psicanálise e Saúde Mental se as intervenções estiverem, sem exceção, pautadas no campo da ética psicanalítica.

Ao apresentar a Psicanálise àqueles que pretendem se tornar analistas, Freud (1912/1990a, 1913/1990b) faz algumas recomendações importantes para nossa reflexão. Dentre elas, uma nos permite dar o primeiro passo no caminho de discorrer sobre o que vem a ser a ética orientada pela Psicanálise, que deve operar as intervenções que se inscrevem no âmbito da clínica em extensão (Jimenez, 1994). Trata-se da afirmação de que "a extraordinária di- 
versidade das constelações psíquicas envolvidas, a plasticidade de todos os processos mentais e a riqueza dos fatores determinantes opõem-se a qualquer mecanização da técnica" (Freud, 1913/1990a, p.164). Por esse motivo, Freud (1913/1990a) optou por lançar mão de recomendações e não regras e, não reivindicando qualquer aceitação incondicional a elas, enfatizou que, diante do que ele expõe ao propor uma teoria e um método capazes de analisar de forma singular as manifestações psíquicas humanas, seria da ordem do impossível qualquer tentativa de formulação de uma técnica única e verdadeira. No entanto, algumas recomendações nos permitem apontar para aquilo que Freud pensou como direção para os analistas, ao proporem qualquer forma de análise ou intervenção que tenha a Psicanálise como referencial teórico.

Tomaremos, então, para refletir sobre tal tema, uma via que considera a Ética da Psicanálise como a ética de um pensamento, de uma prática, que questionou (e questiona até hoje), no Ocidente, alguns pressupostos tradicionais. Na opinião de Kehl (2002), temos que: "a virada freudiana abalou profundamente algumas convicções a respeito das relações do homem com o Bem, exigindo que se repensassem os fundamentos éticos do laço social a partir da descoberta das determinações inconscientes da ação humana" (p. 8).

De acordo com Imbert (2001), a ética a que se propõe a prática psica- nalítica rompe com qualquer tentativa de restituir ao sujeito um comportamento moral ou a aquisição de bons hábitos, o que é prática constante dos discursos médico, pedagógico e psicológico. Como psicanalistas, devemos criar, ou melhor, proporcionar a criação de um espaço que possibilite a emersão do sujeito. Sujeito que é único, por se tratar do sujeito do desejo do inconsciente. Este desejo não pode ser satisfeito, uma vez que, conforme nos alertou Freud, o objeto de desejo do sujeito do inconsciente é inexistente, perdido desde sempre e para sempre. Temos uma das distinções entre a ética e a moral, pois enquanto a última tenta enquadrar o indivíduo a regras previamente estabelecidas, a outra "mantêm-se o mais próximo possível do que é o mais íntimo, o mais singular de outrem, constituindo a própria condição desse íntimo e desse singular" (Imbert, 2001, p.18).

Ao falar da distinção entre ética e bem, Lacan (1991) argumenta que a ética "começa no momento em que o sujeito coloca a questão desse bem que buscara inconscientemente nas estruturas sociais - e onde, da mesma feita, foi levado a descobrir a ligação profunda pela qual o que se apresenta para ele como lei está estreitamente ligado à própria estrutura do desejo" (p. 97). Afirma, ain$\mathrm{da}$, que propor uma leitura sobre a ética só é possível após o reconhecimento da primazia do desejo do sujeito sobre suas ações conscientes, ou 
seja, quando o sujeito consegue relacionar sua ação com o desejo que a habita, e é justamente essa via do desejo que se opõe à ética tradicional.

Para avançarmos nessas questões, Imbert (2001) propõe uma diferenciação entre lei e regra. Ele esclarece que:

a regra é o princípio constitutivo dos hábitos e das formalizações; ela estabelece o vínculo; reúne e mantém o todo unido. Ao proceder desse modo, ela corre o risco de se deixar deslizar pela vertente de uma produção de belas formas, cujo objetivo secreto seria a fabricação-de-uma-imagem, o estabelecimento de um Eu magistral que não cedesse sua independência a não ser aos deuses (...). A ética opõe à regra e a seus efeitos imaginários - através dos quais se elaboram, ao mesmo tempo, a ordem e a coerência de um Eu, de uma Cidade e de um Cosmos - a eficácia da lei que permite aos homens separaremse, além de se sentirem e viverem diferentes (p. 23).

A lei a que o autor se refere não é aquela produtora de normas e regras, ao contrário, sendo justamente o que a diferencia da moral, é ela que, inscrita no inconsciente do sujeito e transmitida simbolicamente pela cultura, estabelece uma separação que diferencia, desliga e liberta o sujeito. Nesse caso, estamos nos referindo à lei que barra o sujeito, aquela que se coloca entre ele e sua mãe, aquela que funda o desejo, operando a separação entre o infans e o Outro. Podemos inferir então, sem termos como pretensão resumir tais questões, que a Ética da Psicanálise seria a ética do 
desejo, a ética do sujeito, que está sempre lançado na busca por um objeto de satisfação. Sendo assim, qualquer tentativa de sobrepor algo ao sujeito, principalmente na forma de um saber soberano, ou de dar a ele algo que lhe cause a ilusão de satisfação plena de suas pulsões e demandas latentes, contrapõe-se ao caminho indicado por Freud, ao qual nos referíamos no início deste texto.

A moral e as leis de conduta não devem servir como guia para fundamentar as relações, uma vez que elas não são se sustentam em tal função. Kehl (2002) atribui à desmoralização do código de condutas uma das causas do que chama de crise ética contemporânea. Ela descreve um enfraquecimento da sustentação simbólica dos códigos que, amparados por uma ordem patriarcal soberana, costumavam regular as relações humanas, determinando a ordem social com lugares de autoridade preestabelecidos. O que vemos hoje, principalmente no que se refere aos discursos médico, pedagógico e psicológico implícitos nas práticas de orientação à saúde e à educação, é uma tentativa de ordenar essas relações a partir, por exemplo, da lógica do amor, que se apresenta como uma regra no discurso da fraternidade cristã, o qual, apesar do declínio simbólico, ainda tem grande influência sobre a civilização. Ao analisar tal discurso sob a perspectiva da Psicanálise, temos que isso é da ordem do impossível, uma vez que o amor incondicional ao próximo determinaria a anulação da diferença que é constitutiva do sujeito. Esse só pode se relacionar com o Outro/outro como semelhante na diferença. Se o sujeito anula a diferença do Outro/outro e o torna idêntico, tende a submetê-lo ao seu gozo como objeto de satisfação. O paradigma dessa anulação é o que acontece na psicose.

A ideia de levar a Ética da Psicanálise às intervenções em Saúde Mental dentro dos serviços públicos de saúde está justamente na tentativa de mudança do olhar que os profissionais têm diante de casos como este que mencionamos. Olhar que impossibilitou que essa família fosse tomada como sujeito, resultando, por exemplo, na retirada do bebê da menina mais nova do seu convívio logo após o nascimento. Um olhar enrijecido sob a contínua tecnicização da prática. Diante dessa proposta, outra questão nos parece relevante para essas reflexões. É possível transmitir um saber, ou seja, esse saber do qual estamos falando, o saber da Ética da Psicanálise, a práticas que não estão enquadradas na clínica psicanalítica clássica? E ainda, é possível fazer essa transmissão a profissionais que não se pretendem analistas, mas que, de alguma forma, dão certa continui- 
dade ao trabalho destes numa instituição de cuidado de saúde?

$\mathrm{Na}$ intenção não de responder, mas de refletir sobre tais questionamentos, lançaremos mão da teoria lacaniana, apresentada na ideia do cartel como forma de funcionamento que torna possível a transmissão da Ética da Psicanálise em intervenções no âmbito da Saúde Mental. Para isso, enfatizamos a função do mais um, que pode tomar diferentes formas encarnando dispositivos que garantam a sustentação da falta, tornando, assim, todo e qualquer saber incompleto diante da singularidade do sujeito.

\section{A estrutura do cartel e ética da psicanálise: 0 savoir-faire com a falta}

O cartel, de acordo com a teoria lacaniana, seria uma forma singular de funcionamento de um pequeno grupo, cuja estrutura garantiria a minimização da dimensão imaginária presente nos grupos em geral, possibilitando, assim, a transmissão da Ética da Psicanálise, ou seja, a ética do sujeito do inconsciente, do desejo. "O cartel não existe em si”" (Trobas, 1994, p. 108); é um órgão de base de trabalho de uma escola de psicanálise que visa à elaboração de um produto que, não sendo coletivo, é próprio de cada participante membro do grupo. De acordo com Trobas (1994), "precisamos con- 
tar com a experiência do cartel e com a transmissão desta para poder tentar uma elaboração de uma clínica do cartel no sentido de um abarcamento do real em jogo no grupo, o único capaz de permitir ao discurso analítico ocupar seu campo" (p. 109).

O que pretendemos é refletir sobre uma forma de funcionamento que garanta não a transmissão da Psicanálise como técnica ou teoria, mas, sim, como ética, como estilo. Conforme Jimenez (1994), o tema da transmissão sempre levantou questões, uma vez que o próprio Freud nos orienta a abrirmos mão do saber que nos foi ensinado sempre que nos defrontamos com um novo caso, pois o saber surge de modo singular diante de cada análise, próprio a um determinado sujeito. A palavra transmissão parece ter uma característica paradoxal, pois está intimamente ligada à ciência. No entanto Lacan não abriu mão dela em seus textos, afirmando, segundo Jimenez (1994), que, em se tratando da Psicanálise, o que se transmite não é um saber, mas, sim, um estilo. "Estilo entendido não como traço diferencial, mas como aquilo que garante que o traço diferencial seja intransmissível: estilo como objeto" Jimenez, 1994, p. 22). Segundo a autora, Lacan propõe duas direções quanto à transmissão. Uma delas seria por meio dos matemas, que são aquilo que do real se transmite. A outra seria o estilo.

Nesse sentido, entenderemos, aqui, estilo não como uma forma de escrever, mas algo da ordem do indefinível, "que toca o ser" (Jimenez, 1994, p. 28), pois:

sendo o estilo o objeto ou, mais precisamente, a queda desse objeto, o estilo seria o impronunciável que atravessa o texto, a causa que desliza entre linhas, o indecifrável que corre entre as palavras. Não é de se estranhar o efeito de beleza, posto que o belo é o último véu a cair antes do desvendamento do objeto. A estrutura metonímica e a estrutura metafórica, enfim, a estrutura da linguagem, com seus jogos de elisão e de acréscimo de sentido, colocam de tal maneira em evidência este objeto que chega a produzir a ilusão de que estilo é a palavra (p. 29).

Para tornar mais claro o que estamos falando, lançamos mão, mais uma vez das palavras da autora, que toma o termo estilo usado na cultura para explicitar o estilo a que nos referimos. "Quando se tenta definir o estilo de um autor, seria esse contorno particular a que se faz referência. Mas como esse contorno toca o indisível, fica evidente que é impossível definir um estilo, que as palavras ficam aquém do objeto" (p. 31). O que se transmite é o estilo, e "transmitir um estilo seria transmitir um certo saber sobra a falta" (Jimenez, 


\section{Artigo}

1994, p. 32), e é justamente a estrutura do cartel que garante a fratura, o recorte, e a falha. Falha esta que só pode ser assegurada por meio da figura do mais um.

O mais um é, na estrutura criada por Lacan, alguém escolhido pelos membros do cartel que tem como uma de suas principais funções a de velar pelos efeitos internos do grupo e provocar a elaboração de um trabalho. Para isso, o mais um representaria "uma espécie de terceiro ausente que orientaria os discursos dos cartelizantes" (Trobas, 1994, p. 38), e, ao mesmo tempo, "um terceiro encarnado, alternativamente, pelos diferentes membros"... (p. 38) "o mais um deve ser qualquer um, uma pessoa, não uma ausência, mas uma presença" ( $p$. 38). Essa é a forma de assegurar, no grupo, uma figura que, numa condição paradoxal, pertence a ele, propiciando uma ligação transferencial que sustentaria o trabalho, e, ao mesmo tempo, não pertence, possibilitando os questionamentos sobre a ideia de que não é possível um saber absoluto garantindo a circulação do saber.

O mais um, assim como os outros integrantes, também deve ter interesse no tema proposto para o trabalho, pois somente por meio do seu próprio interesse é que ele pode motivar a produção de um saber singular a cada produto. Além disso, é ele que, pela sua condição de sujeito castrado, remetido ao não todo saber, seria capaz de transformar uma demanda de ensino, a qual, geralmente, 
se faz para um líder (que pode tomar várias formas) em transferência de trabalho (Jimenez, 1994), ou seja, na desmontagem da transferência neurótica, na qual o sujeito (ou o grupo) demanda o amor e reconhecimento do Outro, para que, assim, haja algo que implique o cuidado independentemente de questões morais. Faz isso por uma via que é a de separar o sujeito (ou o grupo de trabalho) do Outro da transferência sem destituir o laço que o liga à linguagem (Cabas, 1994).

$\mathrm{Na}$ transferência de trabalho, o motor é o desejo de saber que surge da aceitação da impossibilidade de um saber absoluto. É assim que o mais um cumpre outra função, que é a de mover o cartel com seu próprio desejo de saber, cumprindo a transmissão do estilo da psicanálise por meio da transferência de trabalho, "tendo os sujeitos um valor absolutamente secundário ao desejo de saber que os moveria" (Jimenez, Kleeve, Paz, Autran, 1994 p. 139).

Nesse sentido é que propomos tomar a clínica do cartel como referência para a transmissão da ética psicanalítica. Percebemos que os profissionais que atuam em equipes de saúde estão sempre escorregando na posição narcísica de mestria devido, principalmente, a uma hierarquização do poder/saber feita mediante a formação técnica.

De acordo com Alberti (1994), Lacan, quando fundou sua Escola, propôs essa fórmula de funcionamen- to justamente por acreditar pouco nas pessoas: "Lacan nos dá a chance de que o trabalho aconteça, independente das pessoas, desde que elas apliquem efetivamente o funcionamento proposto" (p. 164). A autora explica, ainda, que:

a minha hipótese é de que a fórmula afinada do cartel testemunha um desejo de Lacan, de que em sua Escola teçam-se novas cadeias significantes em torno da coisa freudiana. E por mais ousado que isso possa parecer, isso implica que Lacan propõe o cartel como uma forma de barrar o Outro da suficiência em sua Escola, de maneira que a fórmula afinada do cartel funciona, deste ponto de vista, como a metáfora paterna que barra o gozo do Outro (p. 164).

Quando ponderamos sobre a possibilidade de desespecialização do saber como uma forma eficaz de cuidado ao usuário dos serviços de saúde (como já dissemos, esse é o modelo de cuidado adotado pelos projetos em Saúde Pública), pensamos, justamente, nessa circulação desse, saber a qual só pode ser feita com a presença de um terceiro que interrogue essa posição. Não afirmamos, aqui, que qualquer pessoa poderia se colocar no lugar do mais um, uma vez que sair de fato da posição subjetiva do mestre exigiria um longo trabalho de análise ao qual nem todos têm acesso ou necessitam (uma vez que estamos nos referindo a profissionais de várias áreas do conhecimento que não se pretendem analistas). No entanto acreditamos na ideia de que a falta 
pode ser transmitida, provocando a saída do profissional da posição de mestria de maneira que se dê a transmissão dessa ética à qual nos referimos.

Essa seria então a base de nosso raciocínio. Apoiados na ideia de que transmitir a Ética da Psicanálise seria transmitir um saber sobre a falta, ou melhor, um savoir-faire com a falta, sustentamos a afirmação de que é possível que essa mesma ética esteja presente em outros dispositivos clínicos, mesmo que peripatéticos ${ }^{1}$, desde que, é claro, estejam vinculados às fórmulas que estamos aqui buscando expor. Não se trata de ensinar a Ética da Psicanálise aos grupos de cuidado da saúde, mas, sim, de transmitir essa ética da falta, por meio da distribuição de funções e do deslizamento do saber, as quais seriam uma das funções do mais um.

\section{Conclusão}

É possível destacar que o que fomentou esse trabalho foi a possibilidade de articulação das premissas psicanalíticas com intervenções que se situam num campo que, aparentemente, distanciase da técnica apresentada por Freud e seus sucessores. No entanto, o dia a dia com essa prática, mostrava-nos o quanto a Psicanálise pode contribuir para a estruturação de projetos que se dediquem ao cuidado do sujeito em sofrimento psíquico no campo da Saúde Pública.

O caso apresentado no início deste trabalho veio ao encontro de nossas reflexões acerca da Ética da Psicanálise. Na medida em que tentávamos articular um saber que contemplasse a complexidade da atuação dos profissionais de saúde no âmbito do serviço público (em especial de saúde mental) e as possíveis contribuições da psicanálise para essa prática, vivenciávamos constantemente, junto a essas mulheres, a angustia provocada pelo enfrentamento de nossa (im)potência ante ao cuidado. Nas nossas visitas a casa desta família, vislumbrávamos a tecitura de um laço que em alguns momentos se mostrava forte, possibilitando que interviéssemos na tentativa de construir um espaço que coubesse uma criança naquela estrutura familiar, no desejo daquela menina, e em outros, fraco, ao ponto de não ter impedido que àquele bebê fosse tirado de sua mãe. A menina grávida não foi mãe. Continua menina grávida. 
A questão que se instaura, não como possibilidade de resposta, mas sim, de interlocução com o campo da clínica em extensão, retorna a ideia do que é possível fazer para sustentarmos uma condição de cuidado em estruturas psíquicas nas quais a transferência não se sustenta pela demanda. No caso apresentado, hipotetizamos que ela tenha se sustentado por uma posição de submissão ao que temos tentado expor como a Ética da Psicanálise. Assim, buscamos intervir na condição de sujeitos castrados, faltosos, detentores de um saber não todo.

A partir de todas essas reflexões, o que se produziu foi um saber sobre a clínica, e não uma forma de intervenção (lembrando que essa nunca foi a nossa proposta). Guerra (2005) ressalta que "fazer do 'cada um' uma proposta coletiva para as políticas públicas não significa universalizar intervenções e construir manuais de orientação, mas tomar o particular como orientação na construção de qualquer proposta pública no campo da saúde mental infanto-juvenil" (p. 148).

Com relação a essa clínica do singular dentro das práticas públicas, Lobosque (2001) afirma que a novidade dessa ruptura do modo como se fazia clínica, está, justamente, em tomar o singular dentro do campo do coletivo, abordando o sofrimento psíquico grave nos novos dispositivos assistenciais. Essa forma de cuidado só se sustenta quando a lógica do 


\section{Artigo}

atendimento não se subordina aos procedimentos de consulta e sessão.

Acreditamos que este trabalho tenha um efeito de transmissão ética, permitindo a imersão de outros a partir das reflexões aqui levantadas. Esperamos que esta lógica do cuidado possa ser levada a outros lugares além do consultório padrão.

$\mathrm{O}$ nosso desejo nos leva à crença na possibilidade dessa clínica do desejo, da falta, do sujeito... A nossa prática nos traz a angústia necessária para a concretização desse pensar, desse fazer, que nos seduz a todo momento. E nos faz pensar... e nos faz fazer...

REFLECTIONS ON THE ETHICS OF PSYCHOANALYSIS AND ITS CONTRIBUTION TO MENTAL HEALTH PRACTICE

\section{Abstract}

We aim to reflect this work, draw on psychoanalytic theory, on the (im) possibility of transmission of the ethics of psychoanalysis to practices that fall outside the mold of traditional clinic. We saw that this is possible, since sustained the idea that such transmission occurs when the agent acts from the care provided castrated subjects. Lacan's theory about the function of plus-one, was important to think of organizing a device that regulates the interventions, in that it can operate as the updating of the Other castration, making medical and psychological knowledge (university) uncompleted.

Index terms: ethics; psychoanalysis; mental health; Lacan; Jacques. 
REFLEXIONES SOBRE LA ÉTICA DEL PSICOANALISIS Y SU CONTRIBUCIÓN A LA PRÁCTICA DE LA SALUD MENTAL

\section{RESUMEN}

Nuestro objetivo en este trabajo es reflexionar, apoyados en la teoría psicoanalitica, en la (im)posibilidad de transmisión de la ética del Psicoanálisis a las prácticas que no entran en el molde de la clínica tradicional. Hemos visto que esto es posible, siempre que sostenemos la idea de que dicha transmisión se produce cuando el agente de cuidado actúa a partir de la condición de sujeto castrado. La teoría lacaniana de la función del Más uno, ha sido importante para que pensemos en el montaje de dispositivos que regulen las intervenciones clínicas, a medida que pueden actuar como función que actualiza la castración del Otro interventor, descompletando el saber médico-psicológico (universitario).

Palabras claves: ética; psicoanálisis; salud mental; Lacan; Jacques, 1901-1981.

\section{REFERÊNCIAS}

Arona, E. C. (2010). Implantação do matriciamento nos serviços de saúde de Capivari. Saúde e Saúde, 18 (1), 26-36.

Alberti, S. (1994). O cartel e o Real de uma dissolução. In S. Jimenez (Org.), O cartel: conceito e funcionamento na escola de Lacan (Vol. 1, pp. 161-168). Rio de Janeiro: Campus.

Cabas, A. G. (1994). Do mais-um. In S. Jimenez (Org.), O cartel: conceito e funcionamento na escola de Lacan (pp. 51-55). Rio de Janeiro: Campus.

Freud, S. (1990a). Sobre o início do tratamento: novas recomendações sobre a técnica da Psicanálise. In S. Freud, Edição standard brasileira das obras psicológicas completas de Sigmund Freud (J. Salomão trad., Vol. 12, pp. 163-187). Rio de Janeiro: Imago. (Trabalho original publicado em 1913)

Freud, S. (1990b). Recomendações aos médicos que exercem a psicanálise. In S. Freud, Edição standard brasileira das obras psicológicas completas de Sigmund Freud (J. Salomão trad., Vol. 12, pp. 147-158). Rio de Janeiro: Imago. (Trabalho original publicado em 1912)

Guerra, A. M. C. (2005). A psicanálise no campo da saúde mental infanto-juvenil. Psychê, 9(15), 139-154.

Imbert, F. (2001). A questão da ética no campo educativo (G. J. F. Teixeira, trad.). Petrópolis, RJ: Vozes.

Jimenez, S. (1994). O cartel. In S. Jimenez (Org.), O cartel: conceito e funcionamento na escola de Lacan (pp. 11-34). Rio de Janeiro: Campus.

Jimenez, S., Kleeve P., Paz, V. \& Autran, A. L. (1994). Cartel: do trabalho de transferência à transferência de trabalho. In S. Jimenez (Org.), O cartel: conceito e funcionamento na escola de Lacan (pp. 137-142). Rio de Janeiro: Campus.

Kehl, M. R. (2002). Sobre ética e Psicanálise. São Paulo: Companhia das Letras.

Lacan, J. (1991). O seminário, livro 7: a ética da psicanálise, 1958-1960. Rio de Janeiro: Jorge Zahar.

Lancetti, A. (2008). Clínica peripatética. São Paulo: Hucitec. 


\section{Artigo}

Lei $\mathrm{n}^{\circ}$ 8069, de 13 de Julho de 1990. (1990, 16 de julho). Dispõe sobre o Estatuto da Criança e do Adolescente e dá outras providências. Diário Oficial da União, p. 13.563.

Lobosque, A. M. (2001). Experiências da loucura. Rio de Janeiro: Garamond.

Miguelez, N. B. S. (2007). Complexo de Édipo: novas psicopatologias, novas mulheres, novos homens. São Paulo: Casa do Psicólogo.

Rassial, J. J. (2000). O sujeito em estado limite. Rio de Janeiro: Companhia de Freud.

Trobas, G. (1994). Do grupo ao cartel, do líder ao mais-um. In S. Jimenez (Org.), $O$ cartel: conceito e funcionamento na escola de Lacan (pp. 37-50). Rio de Janeiro: Campus.

carolsantana22@hotmail.com paravidini@ufu.br

Recebido em agosto/ 2010. Aceito em março/ 2011. 